Article

\title{
Automated Real-Time Assessment of Stay-Cable Serviceability Using Smart Sensors
}

\author{
Seunghoo Jeong ${ }^{1}$, Young-Joo Lee ${ }^{1}\left(\mathbb{D}\right.$, Do Hyoung Shin ${ }^{2, *}$ (D) and Sung-Han Sim ${ }^{3, *(\mathbb{C}}$ \\ 1 School of Urban and Environmental Engineering, Ulsan National Institute of Science and \\ Technology (UNIST), Ulsan 44919, Korea; shjeong@unist.ac.kr (S.J.); ylee@unist.ac.kr (Y.-J.L.) \\ 2 Department of Civil Engineering, Inha University, Incheon 22212, Korea \\ 3 School of Civil, Architectural Engineering and Landscape Architecture, Sungkyunkwan University, \\ Suwon 16419, Korea \\ * Correspondence: dshin@inha.ac.kr (D.H.S.); ssim@skku.edu (S.-H.S.)
}

Received: 1 October 2019; Accepted: 17 October 2019; Published: 22 October 2019

\begin{abstract}
The number of cable-stayed bridges being built worldwide has been increasing owing to the increasing demand for long-span bridges. As the stay-cable is one of critical load-carrying members of cable-stayed bridges, its maintenance has become a significant issue. The stay-cable has an inherently low damping ratio with high flexibility, which makes it vulnerable to vibrations owing to wind, rain, and traffic. Excessive vibration of the stay-cable can cause long-term fatigue problems in the stay-cable as well as the cable-stayed bridge. Therefore, civil engineers are required to carry out maintenance measures on stay-cables as a high priority. For the maintenance of the stay-cables, an automated real-time serviceability assessment system using wireless smart sensors was developed in this study. When the displacement of the cable in the mid-span exceeds either the upper or the lower bound provided in most bridge design codes, it is considered as a serviceability failure. The system developed in this study features embedded on-board processing, including the measurement of acceleration, estimation of displacement from measured acceleration, serviceability assessment, and monitoring through wireless communication. A series of laboratory tests were carried out to verify the performance of the developed system.
\end{abstract}

Keywords: stay-cable; serviceability; monitoring; automation; real-time; Raspberry Pi; smart sensor

\section{Introduction}

With increasing demand for long-span bridges, cable-stayed bridges have been widely applied to construction owing to their high structural stiffness and aesthetic appearance [1,2]. Since the construction of the Stromsund bridge as the first modern cable-stayed bridge in Sweden (1955) [3], the maintenance of constructed bridges has received substantial attention to preserve their structural integrity and prolong their service life [4]. Among the various maintenance concerns of cable-stayed bridges, wind-rain-induced vibration has been recognized as one of the primary problems threatening their structural operability and serviceability since its first observation at the Meiko-West Bridge in Japan reported in 1986 [4,5]. A stay-cable, which is one of the most significant load-carrying members of a cable-stayed bridge, is vulnerable to vibrations induced by external loads such as wind, rain, and traffic owing to its inherent low damping ratio with high flexibility [4,6-9]. Among other factors, excessive vibrations in a stay-cable cause long-term fatigue in it and impact the structural integrity of the entire bridge $[4,8,10,11]$. Therefore, civil engineers are required to conduct maintenance measures on high priority to maintain the structural integrity of not only stay-cables but also cable-stayed bridges [4,9-12]. 
The structural integrity of any civil construction can be preserved by maintaining its serviceability and operability within acceptable levels with limited time and financial resources $[4,13]$. Of these two parameters, serviceability tends to be a primary concern in terms of structural safety because users are likely to be sensitive to a serviceability issue far earlier than an operability issue $[4,14]$. Note that serviceability determines the ability of a structure to be used, whereas operability is related to the ability of a system to continue functioning $[4,15]$. As an effort to maintain the safe serviceability of a stay-cable, developed countries have assigned design codes that specify the allowable level of serviceability for bridge users [4]. In the United States, the vibration comfort level is assessed depending on the relationship between cable vibration and cable diameter, which is classified into three levels: "not allowable" when the amplitude of the cable vibration is twice the diameter of the stay-cable, "recommended" when the amplitude is close to the diameter, and "preferred" when the amplitude is approximately half the diameter [16]. The Korean government assigns the acceptable serviceability level of stay-cables based on the amplitude of vibration of the cable at mid-span, which is less than $L / 1600$ under an average oncoming wind speed of less than $20 \mathrm{~m} / \mathrm{s}$ for $10 \mathrm{~min}$, where $L$ is the length of the subject stay-cable [4]. Both the Japanese and Chinese governments assign serviceability levels to cable-stayed bridges based on the deflection at mid-span of the bridge deck, which is less than $L / 2000$ and $L / 400$, respectively [12,17].

Monitoring serviceability with respect to cable vibration should be emphasized as one of the critical maintenance efforts for cable-stayed bridges [4,18-20]. An automated system that assesses the serviceability of stay-cables in real time is required to monitor their serviceability effectively. However, thus far, little work has gone into developing an automated real-time cable serviceability assessment system. Previous studies have focused on reducing vibration of the cable to improve the serviceability level or assessing the level of serviceability of stay-cables. For example, control schemes, such as active, semi-active and hybrid control, and dampers have been proposed and developed for vibration reduction of the cable [21-24]. Furthermore, previous work by Jeong et al. (2019) developed an integrated cable vibration control system using smart sensors which embeds the semi-active control with magneto rheological (MR) damper [8]. With vibration control, a serviceability assessment method was proposed using the first-passage failure probability based on the Korean design code, which specifies a range of acceptable amplitudes for cable vibration [4]. When the vibration of the subject cable was beyond the acceptable vibration level in terms of displacement, it was regarded as a stay-cable serviceability failure. This method is not appropriate for the real-time assessment of cable serviceability because the serviceability is determined based on the probability of serviceability failure during a given period of time. Another previous work evaluated the serviceability of footbridges under human-induced vibrations using long-term measurement data [25]. The serviceability of the bridge was considered a failure when the lateral and vertical accelerations of the structure exceeded the limits of comfortable acceleration provided by the guidelines. While this study demonstrates the serviceability assessment based on vibration data, real-time serviceability monitoring was not considered.

Accordingly, in the present study, an automated real-time cable serviceability assessment system is developed using wireless smart sensors, which can monitor the serviceability of stay-cables effectively. Based on the design code from the United States [16], the serviceability failure of a stay-cable is defined as the case when the displacement of the cable in mid-span exceeds twice the diameter of the stay-cable with upper and lower bound. The serviceability assessment system for stay-cables proposed in this study is developed using the Raspberry Pi platform, which is an open-source single-board computer with low cost and low power consumption. The system features embedded on-board computation, including the acquisition of cable response using the MEMS accelerometer, estimation of displacement from the measured acceleration, serviceability assessment, and monitoring through wireless communication. Bridge inspectors can command the system through wireless communication, prompting it to send information related to the serviceability status of the stay-cable back to the bridge inspectors. A series of laboratory tests are conducted to verify the performance of the developed system. The rest of this paper is composed of four parts. First, the displacement estimation method using 
acceleration data proposed by Lee et al. [26] is explained. Then, the developed wireless automated real-time cable serviceability assessment system is introduced in terms of hardware/software and gateway node/leaf node depending on its functions. Thereafter, the results from laboratory tests conducted to verify the performance of the assessment system are presented.

\section{Displacement Estimation Using Acceleration}

For monitoring the serviceability of the stay-cables, the displacement of the cables was employed as a determinant of their serviceability level based on the criterion from the United States [16], i.e., the displacement of the cable should be less than twice the diameter of the target cable. Various displacement measurement methods have been introduced in the past, including those using contract-type and non-contact-type sensors [27]. Among these, the indirect estimation approach, particularly using an accelerometer, has often been employed to estimate the displacement owing to its convenient installation that is reference-free and relatively low cost [27]. Theoretically, displacement can be obtained by the double integration of acceleration. However, double integration of the measured acceleration results in the low-frequency drift in the estimated displacement caused by unknown initial conditions, sensor noise, and signal discretization [27]. To avoid this problem, Lee et al. [26] proposed a dynamic displacement estimation method, which removes the low-frequency drift error by applying a high-pass filter. The only prior knowledge required is information about the lowest frequency of the stay-cable. This method is appropriate for use with smart sensors, as it avoids low-frequency drift, does not require the initial displacement, provides efficient computation, and has been implemented in a wireless displacement estimation system using smart sensors $[27,28]$. The estimated displacement satisfied the performance in terms of accuracy by comparison with a direct displacement estimation method, such as a laser displacement sensor [26-28]. While this approach cannot estimate the static part of the displacement, dynamic displacement is sufficient to assess the serviceability of a stay-cable using the US criterion employed in this study. Therefore, in this study, the displacement estimation method was applied to develop an automated real-time serviceability assessment system for the stay-cable.

This section briefly describes the displacement estimation method using the measured acceleration proposed by Lee et al. [26]. Let $u$ be the estimated displacement, $\Delta t$ the sampling time of the measurement, and $\bar{a}$ the acceleration measured discretely with uniform sampling time $\Delta t$. The displacement can be estimated by minimizing the following equation which is the discretized form by the trapezoidal rule:

$$
\operatorname{Min} \Pi(u)=\frac{1}{2}\left\|L_{a}\left(L_{c} u-(\Delta t)^{2} \bar{a}\right)\right\|_{2}^{2}+\frac{\lambda^{2}}{2}\|u\|_{2}^{2}
$$

where $L_{a}$ is the integration operator based on the discretized trapezoidal rule, $L_{c}$ is the second-order differential operator, $\|\cdot\|$ is the 2-norm of a vector, and $\lambda$ is the regularization factor that adjusts the degree of regularization as indicated by the second term in the minimization problem. If the regularization factor becomes larger, the zero-displacements are estimated from the measured acceleration. With a low regularization factor, the displacement information becomes meaningless and unstable. Based on the optimal regularization term, the displacement can be derived as Equation (2), which minimizes the difference by the numerical integration of the measured acceleration and considers the regularization term

$$
u=\left(L^{T} L+\lambda^{2} I\right)^{-1} L^{T} L_{a} \bar{a}(\Delta t)^{2}
$$

where $L$ is equal to $L_{a} L_{c}$ and the superscript $T$ denotes the transpose of the matrix. The optimal regularization term is suggested as Equation (3), where $N_{d}$ denotes the number of data points in a time window, as depicted in Figure 1:

$$
\lambda_{\text {optimal }}=46.81 N_{d}^{-1.95}
$$

Note that the overlapping moving time window depicted in Figure 1 was introduced to estimate the accurate displacement at the center, ignoring the errors that may occur at the beginning and end of 
the displacements. Each moving window was used to estimate the displacement based on Equation (2), and the full history of displacements is identical to a collection of estimated displacements at the center of each window. The detailed derivation of the estimation of displacement from the measured acceleration can be found in the previous work by Lee et al. [26].

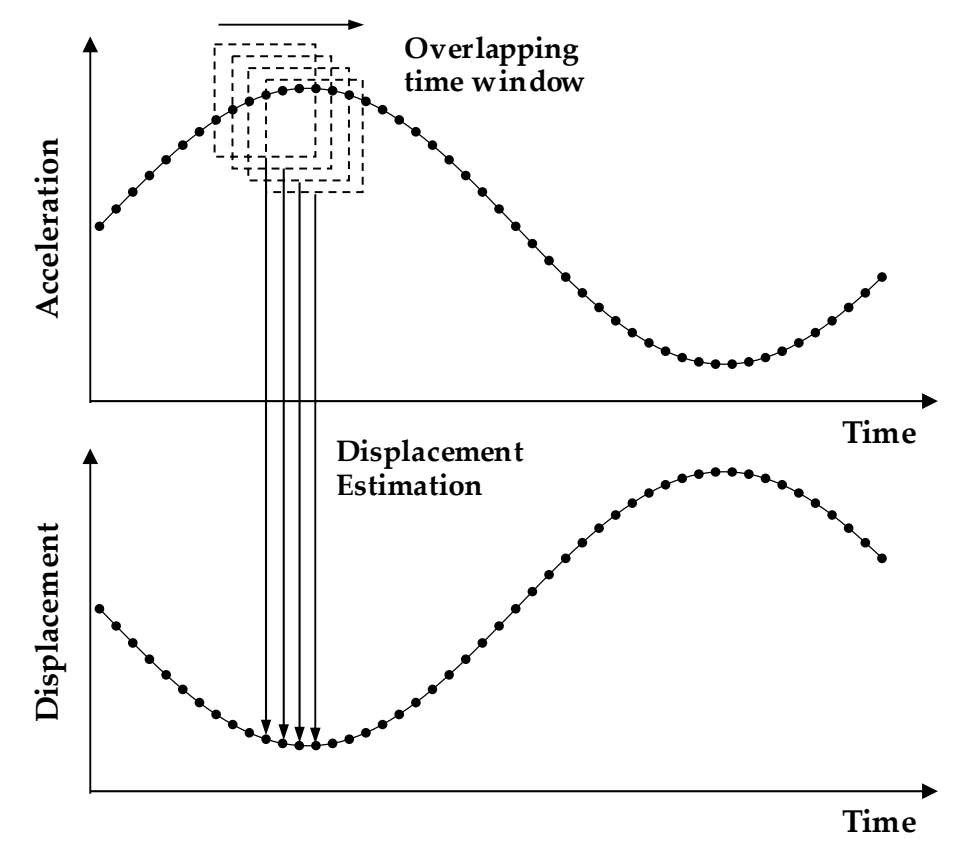

Figure 1. Displacement estimation scheme using overlapping time window.

\section{Automated Real-Time Cable Serviceability Assessment System Using Wireless Smart Sensors}

In this study, an automated real-time monitoring system for cable serviceability assessment is developed using wireless smart sensors (Figure 2). Note that the smart sensors are expected to provide the functions of wireless communication and on-board computation with small size, low cost, and low power consumption [29]. The system is designed to measure the structural acceleration response using a MEMS accelerometer and conduct on-board processing for the estimation of displacement and subsequently evaluate the serviceability. It should be noted that the proposed system in this study is a prototype for realizing the autonomous operation of assessing cable serviceability, and thus a more optimized hardware and software system considering wireless communication and power management shall be required for real-world applications.

The system consists of two types of nodes: a gateway node and a leaf node, as shown in Figure 2. The gateway node is connected to the leaf node through wireless communication and remotely controls it to monitor the serviceability (Figure 2). The leaf node, installed in the mid-span of the cable, assesses the serviceability after the command from the gateway node is received, and features embedded on-board processing using smart sensors that measure the acceleration of the cable and estimate the displacement from the measured acceleration and assess the serviceability of the stay-cable.

The system is composed of hardware and software in both the gateway and the leaf nodes. A When it comes to the hardware of the gateway node, Bluetooth device is used to implement the wireless system. Other wireless communication modules such as LoRa, $\mathrm{WiFi}$, and Zigbee can also be applied to implement wireless communication between the gateway and leaf nodes. Among the various devices that consist of the Bluetooth module, a smartphone was selected-an efficient, user-friendly portable device to check the serviceability condition of the stay-cable. A Samsung Galaxy S10 smartphone equipped with Bluetooth version 5, which can communicate with other devices wirelessly up to 100 $\mathrm{m}$, was selected as the gate node. As the main hardware of the leaf node, a single-board platform, the Raspberry Pi 3 Model B+, was selected for on-board processing (Figure 2). This low-cost and low-power single-board computer is equipped with a $1.4 \mathrm{GHz}$ Quad-Core 64-bit ARMv8 CPU and $1 \mathrm{~GB}$ 
LPDDR2 SDRAM, which demonstrates the capability to carry out the entire embedded processing, from acceleration measurement to serviceability assessment. Furthermore, this hardware possesses HDMI, four USB 2.0 ports, 5 V/2.5 A DC power input, extended 40-pin GPIO headers, 2.4 GHz wireless LAN, Bluetooth 4.2, and a micro SD port for loading the operating system and storing data. Users can access and control the Raspberry Pi 3 Model B+ easily using a keyboard, mouse, and display through HDMI and USB ports. As this single-board computer is equipped with a Bluetooth module, the gateway node can be wirelessly connected to the leaf node, the main hardware of which is the Raspberry Pi 3 Model $\mathrm{B}+$. Further, extended 40-pin GPIO headers aid the single-board computer to control and monitor the external sensors, such as the accelerometer through connections with the electronic circuits. To measure the acceleration, an ADXL335 smart sensor-a small tri-axial MEMS-based analog accelerometer with low cost and low power consumption (Figure 2) -is selected. This MEMS accelerometer is known to measure accelerations up to $3 \mathrm{~g}(270 \mathrm{mV} / \mathrm{g}$ sensitivity) with sampling rates of $0.5-1600 \mathrm{~Hz}$ for the $X$ - and $Y$-axis and $0.5-550 \mathrm{~Hz}$ for the Z-axis. With the analog-based ADXL335 accelerometer, an ADS1115-a 16-bit analog-to-digital converter (ADC) - is used to convert analog acceleration into digitalized acceleration because the Raspberry Pi 3 Model B+ is equipped with GPIO headers with digital input only (Figure 2). The MEMS accelerometer with the ADC sensor can be installed in the mid-span of the stay-cable to measure the vibration of the cable, and these sensing devices are connected to the GPIO headers of the Raspberry Pi model through a jump cable.
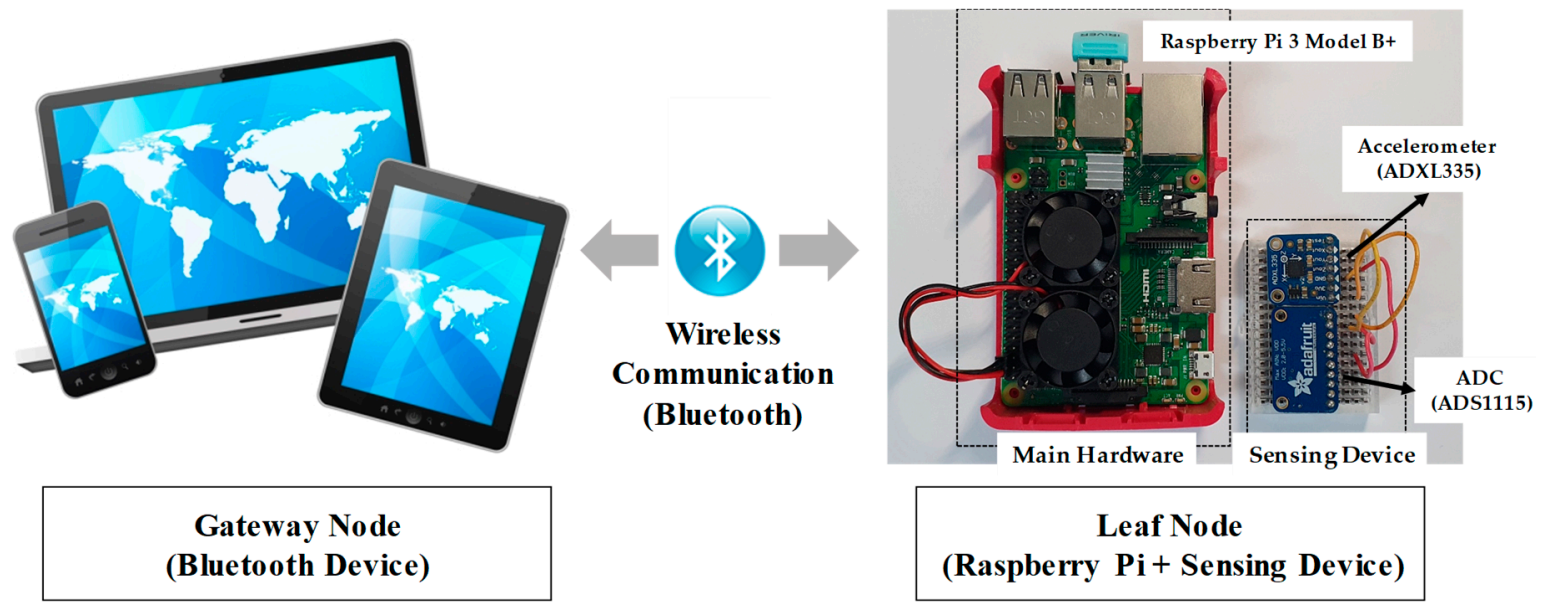

Gateway Node

Figure 2. Design of wireless automated real-time cable serviceability assessment system.

The software layer is designed depending on the functions of the gateway and leaf nodes. BT Chat (https://play.google.com/store/apps/details?id=com.hardcopy.btchat\&hl=ko), which is a free mobile software application used to implement Bluetooth connections between available devices, is installed in the gateway node. When the gateway node is connected to the leaf node through Bluetooth, it commands the leaf node to assess the serviceability level. After the leaf node carries out the assessment, the gateway node receives the status of serviceability from it wirelessly. Inspectors can monitor the serviceability level of a subject cable automatically and in real time using BT Chat, which communicates the maximum amplitude of the cable vibration and a warning message when serviceability is a failure. In the case of leaf nodes, the software algorithm is implemented using Python and embedded to the Raspberry Pi 3 Model B+ running on a Linux operating system. In detail, the software of the leaf node works as follows: when the gateway node commands the leaf node to start monitoring, the leaf node first measures the vibration of the cable in the mid-span using the MEMS accelerometer with an ADC sensor at a sampling rate of $100 \mathrm{~Hz}$. It should be noted that in this study, the sampling time was set to $5 \mathrm{~s}$ to assess the serviceability, which can be changed depending on the users' requirements. Subsequently, the acceleration measured for $5 \mathrm{~s}$ is converted into displacement using the displacement estimation algorithm, and the leaf node evaluates whether the 
maximum amplitude of the estimated displacement exceeds the serviceability criterion which is twice the diameter of the target cable provided by the United States [16]. Thereafter, the leaf node transmits the results, i.e., the maximum displacement and serviceability status, to the gateway node through Bluetooth communication. As mentioned, this system is designed to monitor the serviceability level of the stay-cable every $5 \mathrm{~s}$. The procedure for monitoring the serviceability is graphically described in Figure 3.

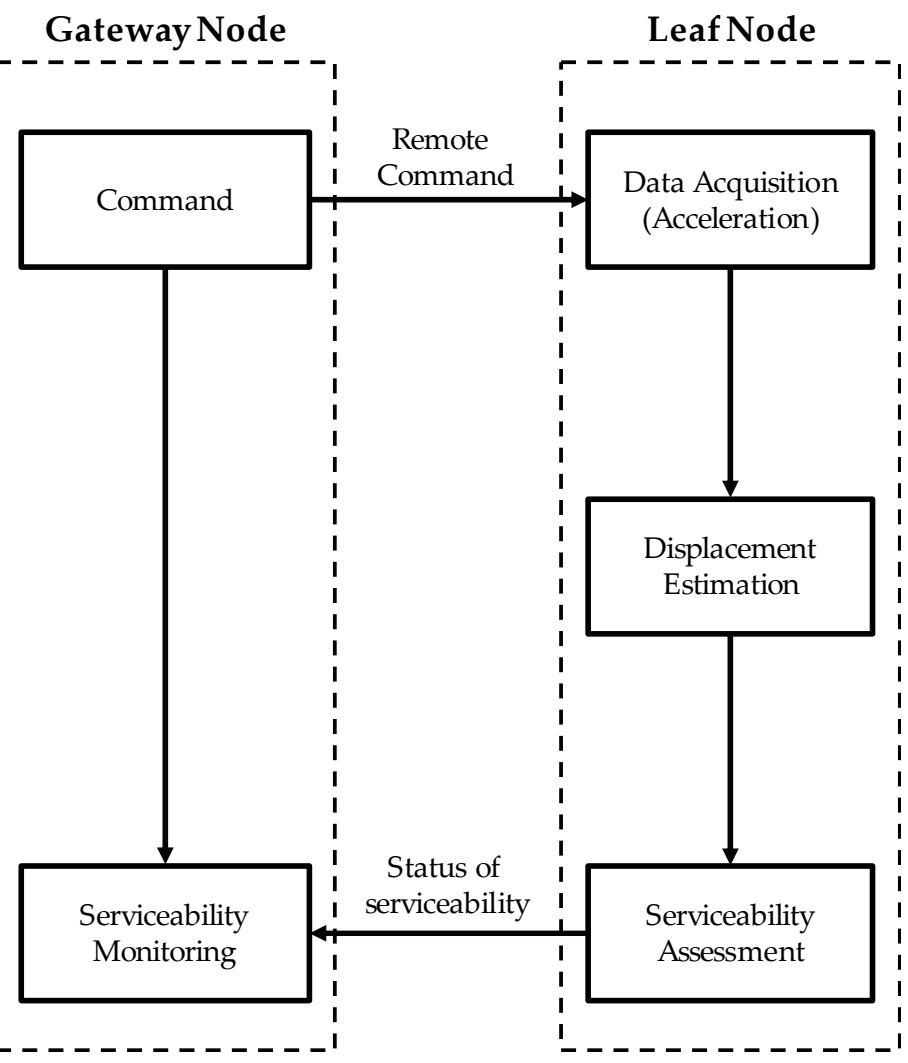

Figure 3. Flowchart for automated real-time cable serviceability assessment.

\section{Experiment}

\subsection{Experimental Setup}

A laboratory-scale experiment was conducted using a cable to verify the performance of the serviceability assessment system, as presented in Figure 4. The physical and geometric properties of the cable are listed in Table 1. The target cable, an IWRC type, has $6.95 \mathrm{~m}$ of length with $43^{\circ}$ inclination, $0.314 \mathrm{~kg} / \mathrm{m}$ of mass density, 5.46 Ton of the break load, and $10 \mathrm{~mm}$ of the diameter. The tension force of the cable was set to be $457.8 \mathrm{~N}$ that is measured using the vibration-based tension estimation method proposed by Shimada [30]. The leaf node was installed on the center of the cable to measure the vibration and assess the serviceability level (Figure 4). To operate the system, external batteries were used to provide power to the single-board computer with the MEMS sensor. In the experiment, an attempt was made to command the leaf node every $5 \mathrm{~s}$ by locating the gateway node $10 \mathrm{~m}$ away from the leaf node. Note that the sampling time for serviceability assessment can be adjusted depending on the inspector's requirements or the criticality of maintenance. A fan located under the cable was used to induce vibration in it with ambient motion, as shown in Figure 4. 


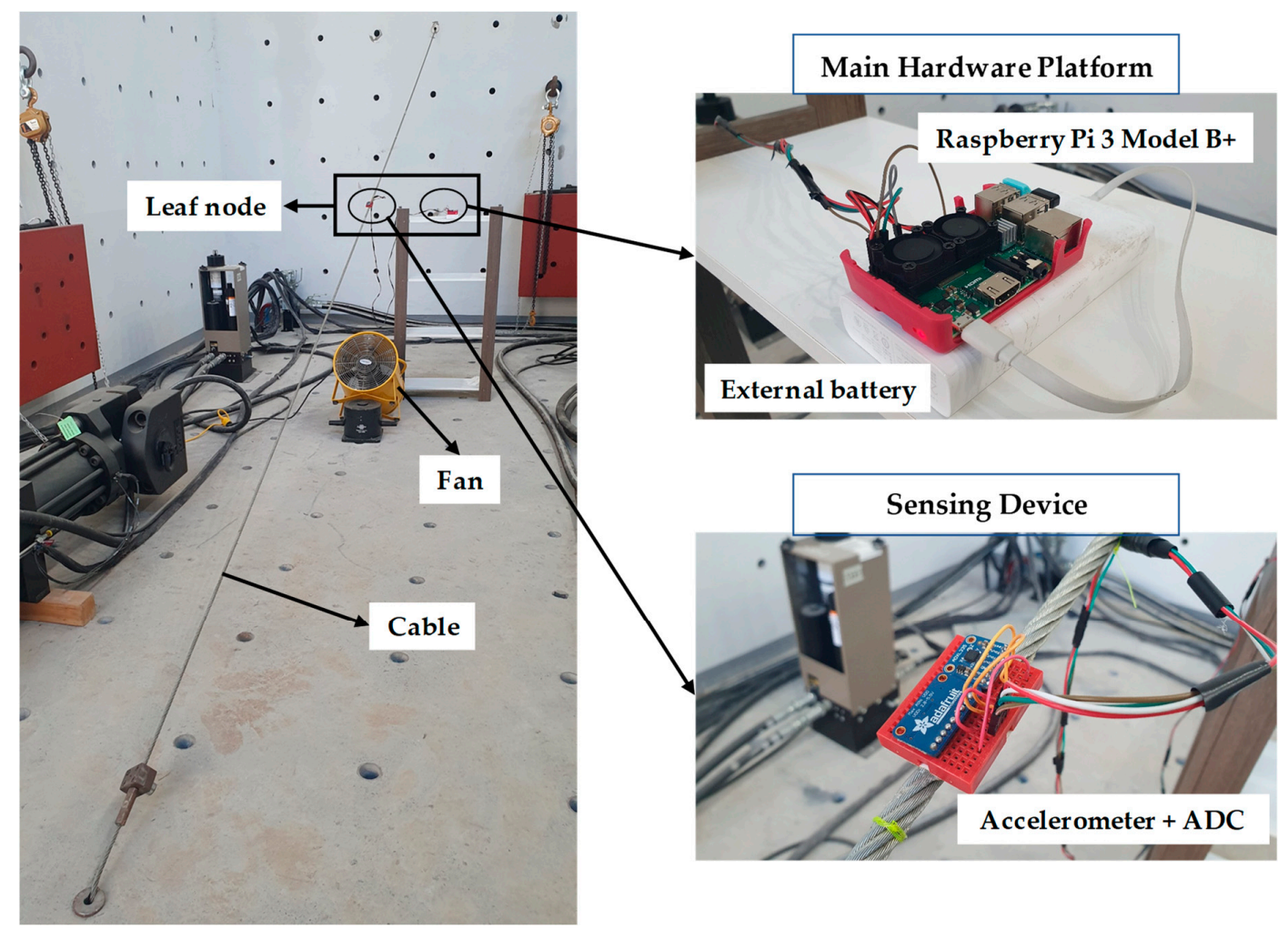

Figure 4. Laboratory setup for monitoring serviceability.

Table 1. Properties of laboratory-scale cable.

\begin{tabular}{ccccccc}
\hline Length $(\mathbf{m})$ & Inclination $\left({ }^{\circ}\right)$ & Tension $(\mathbf{N})$ & Mass $\mathbf{( k g} / \mathbf{m})$ & Diameter $(\mathbf{m m})$ & Break Load (Ton) & Cable Type \\
\hline 6.95 & 43 & 457.8 & 0.314 & 10 & 5.46 & IWRC \\
\hline
\end{tabular}

\subsection{Test of Automated Real-Time Cable Serviceability Assessment System}

A series of laboratory experiments were carried out to test the developed automated real-time serviceability assessment system. These experiments were designed to assess the serviceability level of the stay-cable in mid-span every $5 \mathrm{~s}$. The test results are displayed in Figure 5. The gateway node commanded the leaf node to measure the cable vibration in terms of the acceleration every $5 \mathrm{~s}$, as shown in Figure 5a. The leaf node automatically computed the acceleration-based displacement conversion algorithm to estimate the dynamic displacement every $5 \mathrm{~s}$ (Figure 5b). Finally, the maximum absolute amplitude of the converted dynamic displacement was used to assess the serviceability level, which can be either allowed or disallowed depending on the serviceability criterion (the amplitude should be less than twice the diameter of the target cable; Figure 5c). The serviceability level was evaluated based on the "Max Abs Amp", which denotes the maximum absolute amplitude of the estimated displacement for $5 \mathrm{~s}$. From the results depicted in Figure 5, this study verified that the developed system functioned well to measure the cable response in terms of acceleration, estimate the displacement from the measured acceleration, and assess the serviceability level based on the defined threshold.

Furthermore, the wireless communication between the gateway node and the leaf node was tested to verify the system for serviceability assessment. The result of the wireless communication test between the two nodes is depicted in Figure 6. Because the fan was not sufficiently strong to induce vibrations greater than the failure level of $20 \mathrm{~mm}$, the serviceability threshold was adjusted to $1 \mathrm{~mm}$ just for the purpose of verification. As shown in Figure 6a, wireless communication can be activated after the gateway and leaf nodes are connected through Bluetooth communication by pressing the "Scan for devices" button and selecting the "raspberrypi" as the pairing device in the "Select a 
device to connect" list of the BT Chat application. After the activation of wireless communication, the gateway node commanded the leaf node to measure the acceleration of the stay-cable under the fan vibration, estimate the displacement from the measured acceleration, and assess the serviceability level every $5 \mathrm{~s}$. The serviceability status as well as the maximum absolute amplitude of the estimated displacement for $5 \mathrm{~s}$ were communicated to the gateway node through wireless communication, as shown in Figure 6b. Note that "ua_max" denotes the maximum absolute amplitude of the estimated displacement for $5 \mathrm{~s}$ and the serviceability level is printed as either "Allowable" or "Not allowable" based on the defined threshold of $1 \mathrm{~mm}$. The stay-cable experienced both serviceability allowable and not allowable conditions depending on the assessment cases. For example, in the third assessment case (Figure 6c), the maximum absolute displacement was $0.909 \mathrm{~mm}$ at $1.33 \mathrm{~s}$, which indicates allowable serviceability. In the second example, the maximum absolute displacement was $0.914 \mathrm{~mm}$ at $0.24 \mathrm{~s}$, which is also within the serviceability threshold (Figure 6d). The third example, however, indicated that the serviceability of the stay-cable was a failure because the maximum absolute displacement was $1.230 \mathrm{~mm}$ at $1.68 \mathrm{~s}$, which exceeds the defined threshold (Figure 6e). Thus, this study verified that the developed wireless system can assess the serviceability of the stay-cable automatically and in real time under the defined serviceability threshold through wireless communication between the gateway and leaf nodes.

(a)

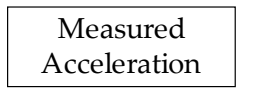

(b)

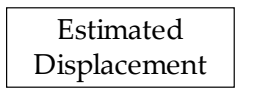

(c)

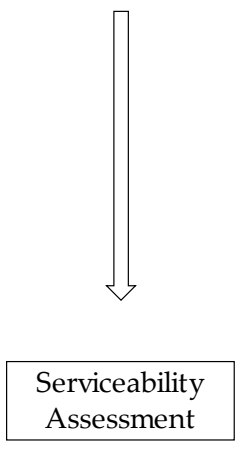

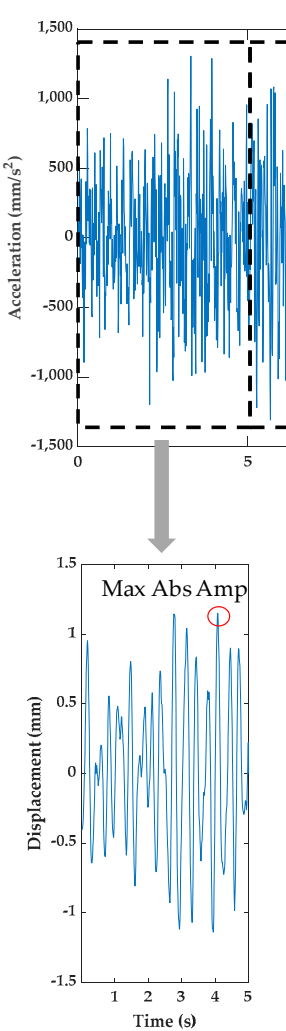

Time

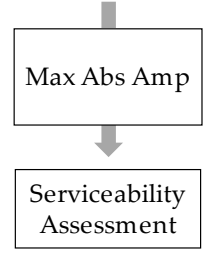

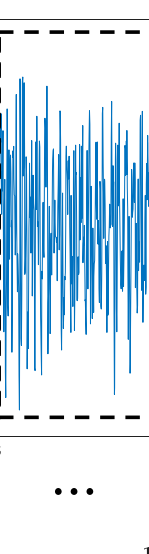
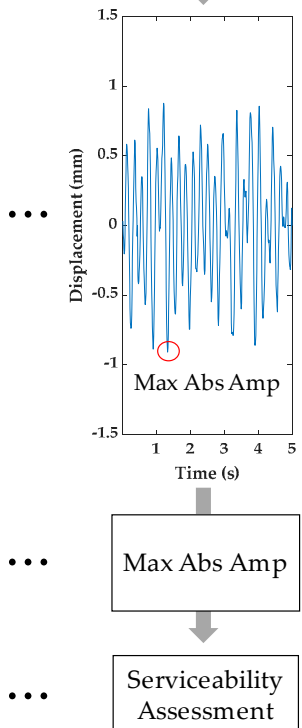
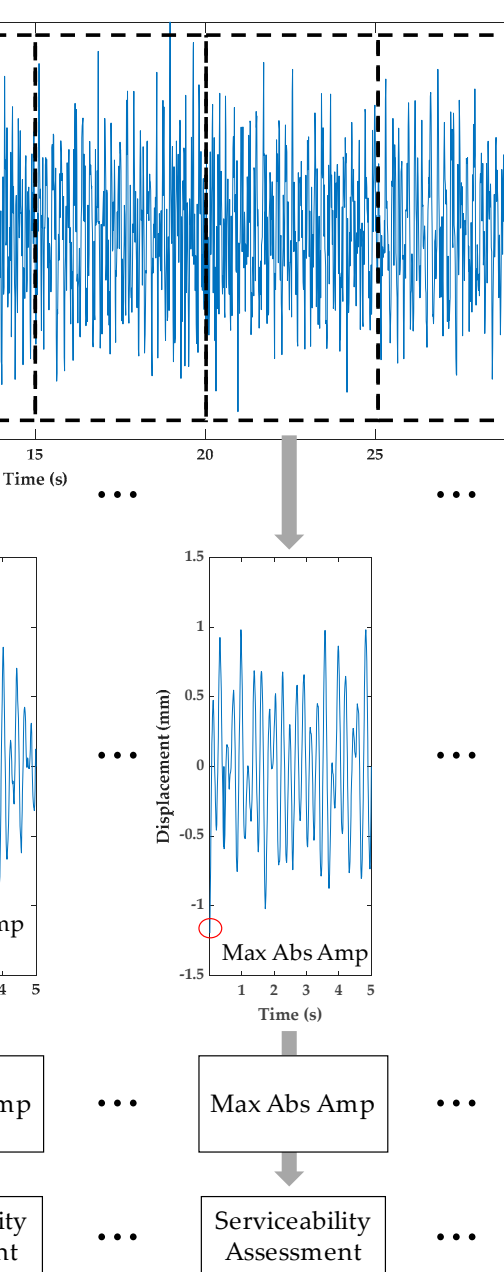

* Max Abs Amp: Maximum Absolute Amplitude

* Serviceability: Allowable/ Not allowable (criterion $=20 \mathrm{~mm}$ )

Figure 5. Automated real-time serviceability assessment results for $30 \mathrm{~s}$. 
(a) Activation of the gateway node

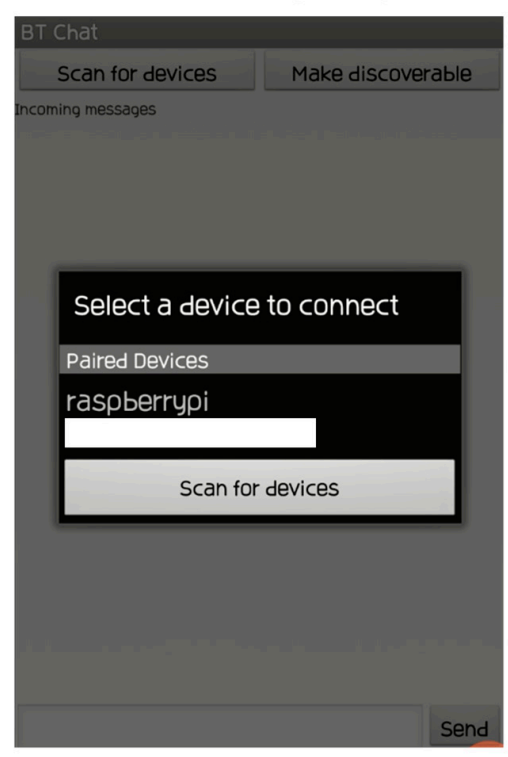

(b) Wireless communication results

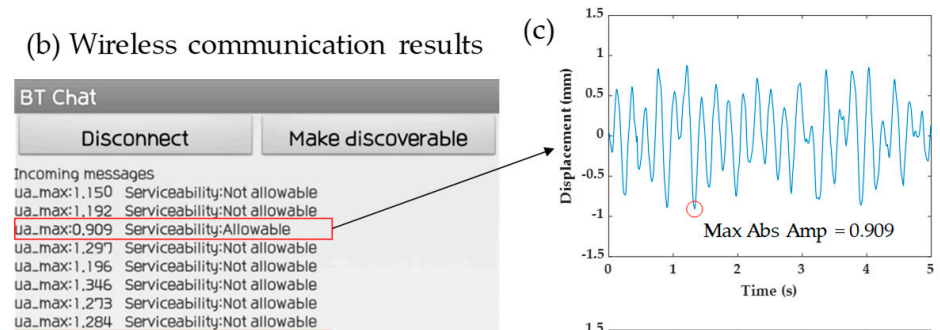

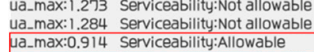

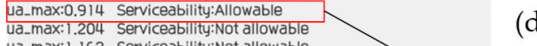

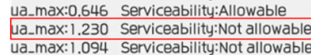

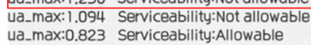
ua_max:0.823 Serviceability:AAlowable
ua_max:0.810 Sevviceability:Allowable

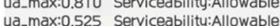

(c)

(d)

1. Max Abs Amp =0.914

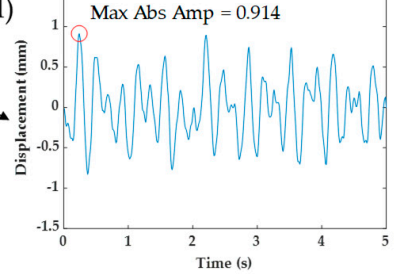

(e)

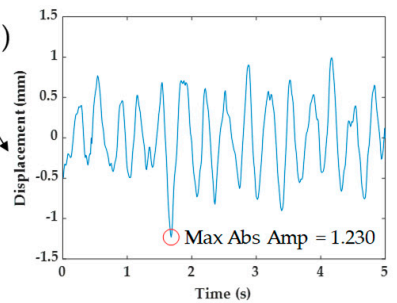

Figure 6. Wireless communication results of serviceability assessment for serviceability threshold of $1 \mathrm{~mm}$.

\section{Conclusions and Discussion}

In this study, an automated real-time serviceability assessment system using wireless smart sensors was developed to monitor the serviceability of the stay-cable in a cable-stayed bridge, which operates at low cost and consumes low power. The developed system consists of a gateway node and leaf node connected to each other through Bluetooth communication. The gateway node commands the leaf node to assess the serviceability and monitor the serviceability level, and the leaf node assesses the serviceability of the stay-cable. The gateway node was designed using a Bluetooth device to check the serviceability condition of the stay-cable. Smart sensors with low cost and low power consumption were used to develop the leaf node, which is based on the Raspberry Pi 3 Model B+ single-board computer and MEMS accelerometer with ADC sensor. The system features embedded on-board processing to measure the acceleration, estimate the displacement from the measured response, and diagnose serviceability failure based on the US design code [16]. Note that the measured acceleration of the stay-cable is converted into dynamic displacement based on a previous study [26]. A series of experiments were conducted using a laboratory-scale cable to verify the developed system, and the results indicate that the system can monitor the serviceability of the stay-cable using a single type of measurement data with the Raspberry Pi-based single-board computer. In addition, the leaf node installed on the cable can be remotely commanded by the gateway node, in particular, using the Bluetooth device, which aids inspectors in monitoring the serviceability level of the stay-cable conveniently. Because the Bluetooth is appropriate for short distance communication, other wireless communication modules such as LoRa, WiFi, and Zigbee can be applied to implement wireless communication between the gateway and leaf nodes in the future work.

As a new pioneering study implementing wireless smart sensors for the maintenance of stay-cables, the developed system can be applied not only for monitoring serviceability but also for other maintenance purposes. For example, a damper system such as a passive, active, and magneto-rheological damper has been widely applied to enhance the damping performance of the stay-cable as a means to reduce the cable vibration $[4,8]$. The developed system can be used to evaluate the performance of the damper in terms of reducing vibration by monitoring the vibration of the cable 
before and after the damper installation. When the serviceability of the stay-cable fails continuously despite the installation of the damper, the developed system allows inspectors to adjust the damper performance to reduce the vibration enough to meet the serviceability criterion. The developed system can be extended to monitor the tension force in the cable by embedding an automated tension estimation algorithm using acceleration data obtained using the vibration-based indirect method. In conclusion, the results of this study are expected to expand present knowledge on the application of smart sensors to monitor the structural health of the stay-cable.

Author Contributions: Conceptualization, S.J. and S.-H.S.; formal analysis, S.J.; methodology, S.J. and S.-H.S.; supervision, D.H.S. and S.-H.S.; validation, Y.-J.L.; writing-Original draft, S.J.; writing-Review and editing, Y.-J.L., D.H.S., and S.-H.S.

Funding: This research was supported by a grant (19SCIP-B128569-03) from Smart Civil Infrastructure Research Program funded by Ministry of Land, Infrastructure and Transport of Korean government.

Conflicts of Interest: The authors declare no conflict of interest.

\section{References}

1. Kim, S.W.; Jeon, B.G.; Kim, N.S.; Park, J.C. Vision-based monitoring system for evaluating cable tensile forces on a cable-stayed bridge. Struct. Health Monit. 2013, 12, 440-456. [CrossRef]

2. Cho, S.; Yim, J.; Shin, S.W.; Jung, H.J.; Yun, C.B.; Wang, M.L. Comparative field study of cable tension measurement for a cable-stayed bridge. J. Bridge Eng. 2012, 18, 748-757. [CrossRef]

3. Podolny, W.; Fleming, J.F. Historical development of cable-stayed bridges. J. Struct. Div. 1972, 98, $2079-2095$.

4. Jeong, S.; Lee, Y.J.; Sim, S.H. Serviceability Assessment Method of Stay Cables with Vibration Control Using First-Passage Probability. Math. Probl. Eng. 2019, 2019, 4138279. [CrossRef]

5. Chen, Z.Q.; Wang, X.Y.; Ko, J.M.; Ni, Y.Q.; Spencer, B.F.; Yang, G.; Hu, J.H. MR damping system for mitigating wind-rain induced vibration on Dongting Lake Cable-Stayed Bridge. Wind Struct. 2004, 7, $293-304$. [CrossRef]

6. Maślanka, M.; Sapiński, B.; Snamina, J. Experimental study of vibration control of a cable with an attached MR damper. J. Theor. Appl. Mech. 2007, 45, 893-917.

7. Fujino, Y.; Kimura, K.; Tanaka, H. Cable vibrations and control methods. In Wind Resistant Design of Bridges in Japan; Springer: Tokyo, Japan, 2012; pp. 197-229.

8. Jeong, S.; Lee, J.; Cho, S.; Sim, S.H. Integrated cable vibration control system using Arduino. Smart Struct. Syst. 2019, 23, 695-702.

9. Kim, J.T.; Nguyen, K.D.; Huynh, T.C. Wireless health monitoring of stay cable using piezoelectric strain response and smart skin technique. Smart Struct. Syst. 2013, 12, 381-397. [CrossRef]

10. Johnson, E.A.; Christenson, R.E.; Spencer, B.F., Jr. Semiactive damping of cables with sag. Comput.-Aided Civ. Inf. Eng. 2003, 18, 132-146. [CrossRef]

11. Li, H.; Liu, M.; Li, J.; Guan, X.; Ou, J. Vibration control of stay cables of the shandong binzhou yellow river highway bridge using magnetorheological fluid dampers. J. Bridge Eng. 2007, 12, 401-409. [CrossRef]

12. Cheng, J.; Xiao, R.C. Serviceability reliability analysis of cable-stayed bridges. Struct. Eng. Mech. 2005, 20, 609-630. [CrossRef]

13. Diamantoulaki, I.; Angelides, D.C. Risk-based maintenance scheduling using monitoring data for moored floating breakwaters. Struct. Saf. 2013, 41, 107-118. [CrossRef]

14. Živanović, S.; Pavic, A.; Reynolds, P. Vibration serviceability of footbridges under human-induced excitation: A literature review. J. Sound Vib. 2005, 279, 1-74. [CrossRef]

15. Jenelius, E.; Petersen, T.; Mattsson, L.G. Importance and exposure in road network vulnerability analysis. Transp. Res. A:-Pol. Pract. 2006, 40, 537-560. [CrossRef]

16. Kumarasena, S.; Jones, N.P.; Irwin, P.; Taylor, P. Wind Induced Vibration of Stay Cables (No. RI-98-034); Missouri, Department of Transportation. Research Development Technology Division: Jefferson City, MO, USA, 2005.

17. Samim, F.; Nakamura, S. Static and seismic characteristics of cable-stayed bridges with new stay systems. In Proceedings of the IABSE Symposium, Geneva, Switzerland, 23-25 September 2015; Association for Bridge and Structural Engineering: Zürich, Switzerland, 2015; Volume 105, pp. 1-8. 
18. Estes, A.C.; Frangopol, D.M. Bridge lifetime system reliability under multiple limit states. J. Bridge Eng. 2001, 6, 523-528. [CrossRef]

19. Minervino, C.; Sivakumar, B.; Moses, F.; Mertz, D.; Edberg, W. New AASHTO guide manual for load and resistance factor rating of highway bridges. J. Bridge Eng. 2004, 9, 43-54. [CrossRef]

20. Jeong, Y.; Kim, W.; Lee, I.; Lee, J. Bridge inspection practices and bridge management programs in China, Japan, Korea, and US. J. Struct. Integr. Maint. 2018, 3, 126-135.

21. Johnson, E.A.; Baker, G.A.; Spencer, B.F.; Fujin, Y. Semiactive damping of stay cables. J. Eng. Mech. 2007, 133, 1-11. [CrossRef]

22. Li, H.; Liu, M.; Ou, J. Vibration mitigation of a stay cable with one shape memory alloy damper. Struct. Control Health Monit. 2004, 11, 21-36. [CrossRef]

23. Ubertini, F. Active feedback control for cable vibrations. Smart Struct. Syst. 2008, 4, 407-428. [CrossRef]

24. Faravelli, L.; Fuggini, C.; Ubertini, F. Toward a hybrid control solution for cable dynamics: Theoretical prediction and experimental validation. Struct. Control Health Monit. 2010, 17, 386-403. [CrossRef]

25. Hu, W.H.; Moutinho, C.; Caetano, E.; Magalhães, F.; Cunha, A. Continuous dynamic monitoring of a lively footbridge for serviceability assessment and damage detection. Mech. Syst. Signal Process. 2012, 33, 38-55. [CrossRef]

26. Lee, H.S.; Hong, Y.H.; Park, H.W. Design of an FIR filter for the displacement reconstruction using measured acceleration in low-frequency dominant structures. Int. J. Numer. Methods Eng. 2010, 82, 403-434. [CrossRef]

27. Park, J.W.; Sim, S.H.; Jung, H.J. Development of a wireless displacement measurement system using acceleration responses. Sensors 2013, 13, 8377-8392. [CrossRef]

28. Moreu, F.; Jo, H.; Li, J.; Kim, R.E.; Scola, S.; Spencer, B.F.; LaFave, J.M. Reference-free displacement estimation and assessment for railroad bridges using wireless smart sensors. J. Bridge Eng. 2015, 21.

29. Sim, S.H.; Li, J.; Jo, H.; Park, J.W.; Cho, S.; Spencer, B.F.; Jung, H.J. A wireless smart sensor network for automated monitoring of cable tension. Smart Mater. Struct. 2013, 23, 025006. [CrossRef]

30. Shimada, T. Estimating method of cable tension from natural frequency of high mode. Doboku Gakkai Ronbunshu 1994, 501, 163-171. [CrossRef]

(C) 2019 by the authors. Licensee MDPI, Basel, Switzerland. This article is an open access article distributed under the terms and conditions of the Creative Commons Attribution (CC BY) license (http://creativecommons.org/licenses/by/4.0/). 